\title{
EVALUATION OF USABILITY OF MAPS OF DIFFERENT SCALES PRESENTED IN AN IN-CAR ROUTE GUIDANCE AND NAVIGATION SYSTEM
}

\author{
Avaliação da usabilidade de mapas em diferentes escalas apresentadas em \\ um sistema de navegação e guia de rota em automóvel \\ Ana Paula Marques Ramos ${ }^{1}$ - ORCID: 0000-0001-6633-2903 \\ Edmur Azevedo Pugliesi² - ORCID: 0000-0003-3426-6619 \\ Renan Furlan de Oliveira² - ORCID: 0000-0002-1361-0356 \\ Vilma Mayumi Tachibana² - ORCID: 0000-0002-8804-6163 \\ Mônica Modesta Santos Decanini² \\ ${ }^{1}$ Universidade do Oeste Paulista, Pós-Graduação em Meio Ambiente e Desenvolvimento Regional, \\ Presidente Prudente - São Paulo, Brasil. \\ E-mail: anaramos@unoeste.br \\ ${ }^{2}$ Universidade Estadual Paulista, Departamento de Cartografia, Pres. Prudente - São Paulo, Brasil. \\ E-mail: edmur@fct.unesp.br; renanfurlanoliveira@hotmail.com; vilma@fct.unesp.br; \\ monca@fct.unesp.br
}

Received in February 27 2017

Accepted in June $11^{\text {th }}, 2018$

\section{Abstract:}

Noise from the information communication process produced by the interfaces of navigation systems has overloaded drivers' cognitive processing systems and increased the probability of traffic accidents. This work evaluates the usability of maps of different scales in a prototype route guidance and navigation system. The maps were designed on basic cartographic communication principles, such as perceptive grouping and figure-ground segregation, as well drivers' requirements for performing a tactical task. Two different scales were adopted, 1:3,000 and 1:6,000, and the maps implemented in the prototype. A total of 52 subjects ( 26 males and 26 females) participated in an experiment performed in a driving simulator. The maps describe an urban route composed of 13 simple and complex maneuvers. The drivers' mental workload was measured in terms of visual demand, navigational error and subjective preference. Results reveal that the usability of maps is influenced by map scale variation, and this is related to maneuver complexity. Also, an association between drivers' visual demand and gender was found, and this was related to drivers' spatial ability. More implications are presented and discussed.

Keywords: In-car Route Guidance and Navigation System; cartographic design; mental workload; usability.

How to cite this article: Ramos, A. P. M. et al. Evaluation of usability of maps of different scales presented in an in-car route guidance and navigation system. Bulletin of Geodetic Sciences, Vol. 24 (3), 383-406, Jul-Sept, 2018. 


\section{Resumo:}

Ruídos nos processos de comunicação da informação em interfaces de sistemas de navegação têm sobrecarregado o sistema de processamento cognitivo dos motoristas e aumentado as chances de acidentes de trânsito. Esse trabalho avalia a usabilidade de mapas em diferentes escalas para um protótipo de sistema de navegação e guia de rota em automóvel. Projetou-se mapas de acordo com os princípios da comunicação cartográfica, tal como segregação de figura-fundo e agrupamento perceptivo, bem como na demanda do usuário ao realizar a tarefa tática. Duas escalas foram adotadas, 1:3.000 a 1:6.000, e os mapas implementados no protótipo. Um total de 52 motoristas (26 homens e 26 mulheres) participaram de um experimento em simulador de direção. Os mapas representaram uma rota em área urbana composta por 13 manobras simples e 13 complexas. A carga mental de trabalho dos motoristas foi quantificada em termos de demanda visual, erro navegacional e preferência subjetiva. Os resultados mostram que a usabilidade dos mapas é influenciada pela variação da escala cartográfica, e isto está relacionado a complexidade da manobra. Além disso, a demanda visual está associada ao gênero do motorista, e isto tem relação com a habilidade espacial. Mais implicações são apresentadas e discutidas.

Palavras-chave: Sistemas de Navegação e Guia de Rota em Automóvel; projeto cartográfico; carga mental de trabalho; usabilidade.

\section{Introduction}

Driving requires a significant mental workload. Route Guidance and Navigation Systems (RGNS) offer greater mobility to drivers to accomplish their navigation tasks. Navigation tasks are divided into two main stages (Michon 1985, Burnett 1998). While route planning does not involve any kind of movement, for the route following task it is supposed a route has been selected previously (Golledge 1999). When following a route, an RGNS should assist drivers at different stages, and one of the main task is called the tactical task which refers to the preparation for achieving the next maneuver (Michon 1985, Pugliesi, Decanini and Tachibana 2009). In this research work, the term maneuver is employed to indicate any kind of direction change in the same road or between different roads.

There are numerous human factor issues regarding RGNS, but the research themes for the design of these systems may be categorized under three principal headings: choice of information, presentation of information and individual characteristics of the drivers (Burnett 1998; Pugliesi et al. 2013). However, the issue 'presentation of information' refers to one of the most relevant concerns in the Human-Machine Interaction area in recent years (Jama 2004, Nhtsa 2012) as it has direct implications on driver safety. According to Ranney, Baldwin and Smith (2013), when an individual performs a secondary task concurrently with a primary one, their performance of the primary task may be reduced. For in-car navigation tasks, driving the vehicle represents the primary task and interaction with RGNS refers to the driver's secondary task of (Pugliesi et al. 2013).

To mitigate the risks related to the process of divided attention between RGNS interfaces and the road, the usability issues of maps presented by these systems have been increasingly under investigation in recent decades (Labiale 2001, Liu 2001, Uang and Hwang 2003, Ho and Li 2004, Lee, Forlizzi and Hudson 2008, Sheleiby, Malek and Alesheikh 2008, Pugliesi, Decanini and 
Tachibana 2009, Pugliesi and Decanini 2009, Lavie and Oron-Gilad 2013). The usability of RGNS has been evaluated in terms of quantifying the mental workload of drivers, using both objective (e.g.: navigational error, visual demand) and subjective (e.g.: drivers' preference) measures according the navigation task performed (Pugliesi et al. 2013). For the road safety issue, the tactical task is assigned to the more critical stage of navigation task because it requires that drivers manipulate, in a few of seconds, a great deal of information to prepare for the next maneuver (Burnett 1998, Labiale 2001, Kaber et al. 2012).

Wickens et al. (2004) state that manipulating a set of elements in a short time requires extensive mental processing from an individual. Thus, when the demands of the task exceed its processing capability, they adjust their strategies to meet the goals of the task or reduce(s) their performance as a compensation process for the required effort (Dingus and Hulse 1993, Young and Stanton $2005,2006)$. Pugliesi et al. (2013) argue that an overload in the human processing system may be increased when an individual has difficulties reading an interface. In cartography, these difficulties are called 'noises in the cartographic communication process'.

Several works (Lavie, Oron-Gilad and Meyer 2011, Lavie and Oron-Gilad 2013) suggest that the main reason for the low use of maps with RGNS is the lack of matching between level of detail of maps and drivers' requirements at different stages of the navigation task. Legibility problems of maps, especially when they are presented in small displays, is another issue for the low usability of RGNS interfaces. Among efforts to solve noises like these in the communication information process, map scale selection should be highlighted (Uang and Hwang 2003, Ho and Li 2004, Lee, Forlizzi and Hudson 2008, Sheleiby, Malek and Alesheikh 2008, Li 2010, Marques, Decanini and Pugliesi 2012, Ramos et al. 2016).

Scale refers to a key variable in the cartographic communication process as it determines selection, generalization and representation of symbols on maps (Dent, Torguson and Hodler 2009, Slocum et al. 2009). Map scale selection according to user's demand may favor rapid information comprehension and this may imply less distraction of drivers on the road. However, it has been noted that, to select scales for maps for RGNS, the different stages involved in the navigation task and the use of an audio-dynamic map in heading-up orientation (egocentric view) to present information to drivers have not been considered. One exception found in the literature review is the work of Ramos et al. (2016) but these authors evaluated maps for RGNS at different scales using only subjective measures and the experiment was performed with a group of drivers during the day in a vehicle parked on the road. Therefore, a driving simulator test including objective measures is still required for overall usability evaluation.

Audio-dynamic representations reduce mental workload for drivers (Labiale 2001, Liu 2001). Furthermore, maps improve the visual searching process in heading-up orientation as they do not require an individual to execute a mental rotation of the map to match the orientation of the roads (Dingus and Hulse 1993). The following question might therefore be raised: "To what extent does scale interfere with the usability of audio-dynamic maps in heading-up orientation when drivers perform this tactical task in urban areas?".

The aim of this work is to evaluate the usability of maps presented at different cartographic scales in an In-Car Route Guidance and Navigation System. The questions addressed are: "Which map scales show higher levels of distraction for drivers?"; "Do drivers make the same/as many (?) navigational errors when they navigate supported by maps in different scales?"; "Which scale is preferred by drivers for performance of navigation tasks?" and "Do relationships exist between driver performance and group characteristics when they navigate supported by maps of different 
scales?". We hypothesize that the level of simplification of audio-dynamic maps in heading-up orientation affects both driver satisfaction and performance in tactical task development and this is related to the complexity of maneuvers. The next section presents the method used in this research, it is therefore important to emphasize that all methods applied are essentially based on the approach of Pugliesi, Decanini and Tachibana (2009).

\section{Method}

\subsection{Subjects}

A total of 52 subjects ( 26 males and 26 females), from the town of Presidente Prudente, located in the state of Sao Paulo, Brazil, took part voluntarily in this experiment. Four criteria were adopted in selecting the participants: having a driving license and at least two years' driving experience; having normal color vision, as people with color deficiency may not be able to identify colored symbols on maps according to Maceachren (1995) and Rigden (1999); having little or no knowledge of the city used in the experiment and being less than 40 years old. Age effects impair the focal accommodation process (Sekuler and Sekuler 2000) and this may interfere with driver performance in the navigation task. All these criteria match approaches relating to the evaluation of RGNS interfaces such as Labiale (2001), Pugliesi, Decanini and Tachibana (2009) and ChingTorng, Hsin-Chieh and Ting-Yen (2010). The group characteristics of drivers are shown in Table 1. All data were collected using a questionnaire.

Table 1: Group characteristics of the 52 participants.

\begin{tabular}{lccc}
\hline \multirow{2}{*}{ Gender } & \multicolumn{3}{c}{ Age } \\
\cline { 2 - 4 } & Minimum & Maximum & Mean and Standard Deviation (SD) \\
\hline Female & 21 & 37 & $27.5(4.83)$ \\
Male & 22 & 38 & $28.6(4.41)$ \\
Mean & 21.5 & 37.5 & $28.05(4.62)$ \\
\hline
\end{tabular}

$\mathrm{SD}=$ Standard Deviation

To measure the spatial ability of the 52 drivers the Perspective Taking/Spatial Orientation Test (PT/SOT) developed by University of California Santa Barbara (Hegarty and Waller 2004) was applied. According to Hegarty and Waller (2004), this test's 12 items assess the ability to imagine different perspectives or orientations in space. Thus, for each item, a picture is shown of an array of objects at the top of the page and an 'arrow circle' with a question about the direction between some objects at the bottom (Figure 1). The test should be performed in 5 minutes. The score for each item is the absolute deviation in degrees between the participant's response and the correct direction to the target (absolute directional error). A participant's total score is the average deviation across all attempted items (Hegarty and Waller 2004). 


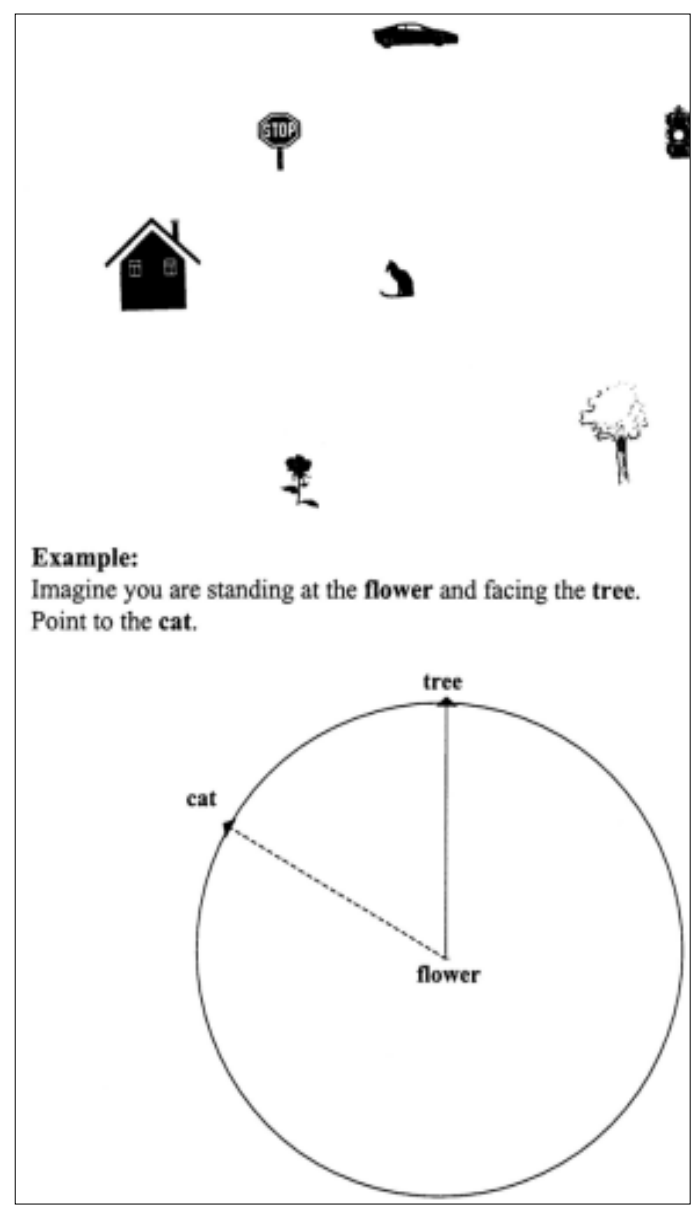

Figure 1: PT/SOT.

Source: Hegarty and Waller (2004)

\subsection{Apparatus}

The experiment was conducted on a low-cost and fixed-base driving simulator (Figure 2). Usability tests of RGNS interfaces have been performed in driving simulators or directly in field (Pugliesi et al. 2013). The choice of a simulated environment over a real environment was for safety concerns.
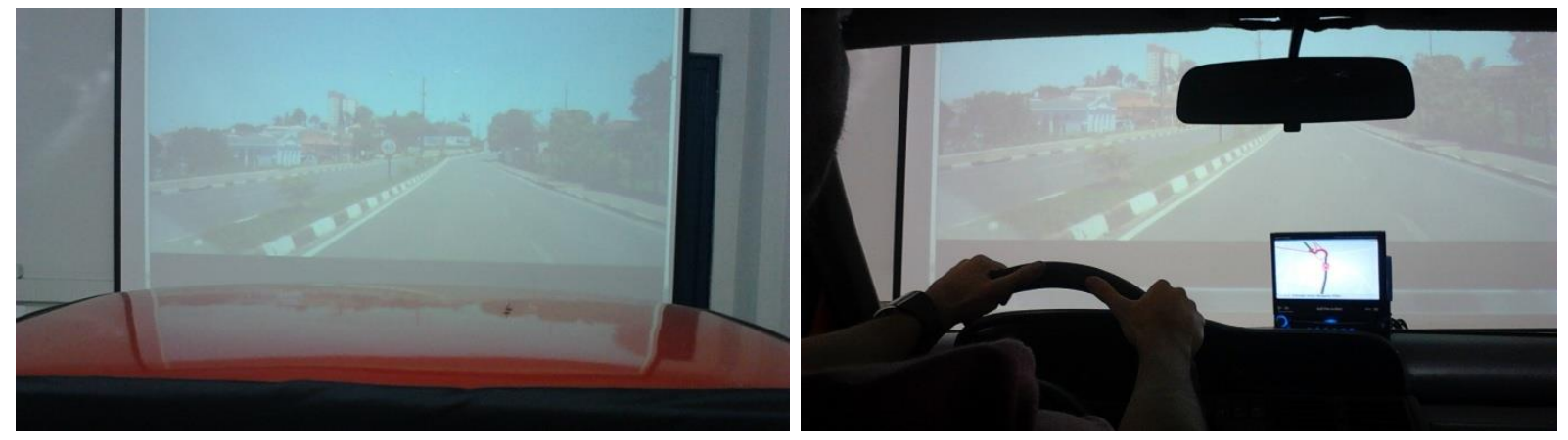

Figure 2: Low-cost and fixed-base driving simulator used on test with the 52 participants. Source: Author. 
The simulator has two output channels: a projector with a resolution of $1024 \times 768$ to display the video movie of the road test on a large screen-image (180 cm height and $240 \mathrm{~cm}$ width) in front of the vehicle, and a 7-inch LCD screen (1024 x 768) to display RGNS maps. The distance between the large screen and the vehicle was $2.50 \mathrm{~m}$. The small-screen was located on the vehicle dashboard to the right side of the steering wheel to represent the Head-Up Display (HUD) position as recommended by Wittmann et al. (2006). The size and resolution of the LCD screen was determined according what has been adopted for RGNS models. The camera of an Asus tablet with a resolution of $1024 \times 768$ was placed next to the LCD screen to capture the eye movements and responses of drivers. The responses were used to analyze the navigational errors for each map scale.

\subsection{Map design}

The design of maps for RGNS requires a decision about a set of variables: selection of study area, choice of display size, determination of map scale, selection and organization of information elements, also decisions about graphic design of maps. Each of these decisions is described below.

\subsubsection{Study area}

A town, Álvares Machado, located in Sao Paulo state, was chosen as the study area for this work (Figure 3). The experimental route selected is composed of 13 decision points (maneuvers) throughout its $3.4 \mathrm{~km}$ length. These decision points were classified as simple or complex maneuvers. Simple maneuvers are decision points at which the driver is provided with a navigation choice of turning right or left only (Pugliesi, Decanini and Tachibana 2009). However, complex maneuvers are decision points at which the driver is provided with several navigation choices which could make the decision process more difficult (Labiale 2001, Pugliesi, Decanini and Tachibana 2009). Roundabouts are an example of a complex maneuver as they contain multiple exits. The experimental route includes three roundabouts.

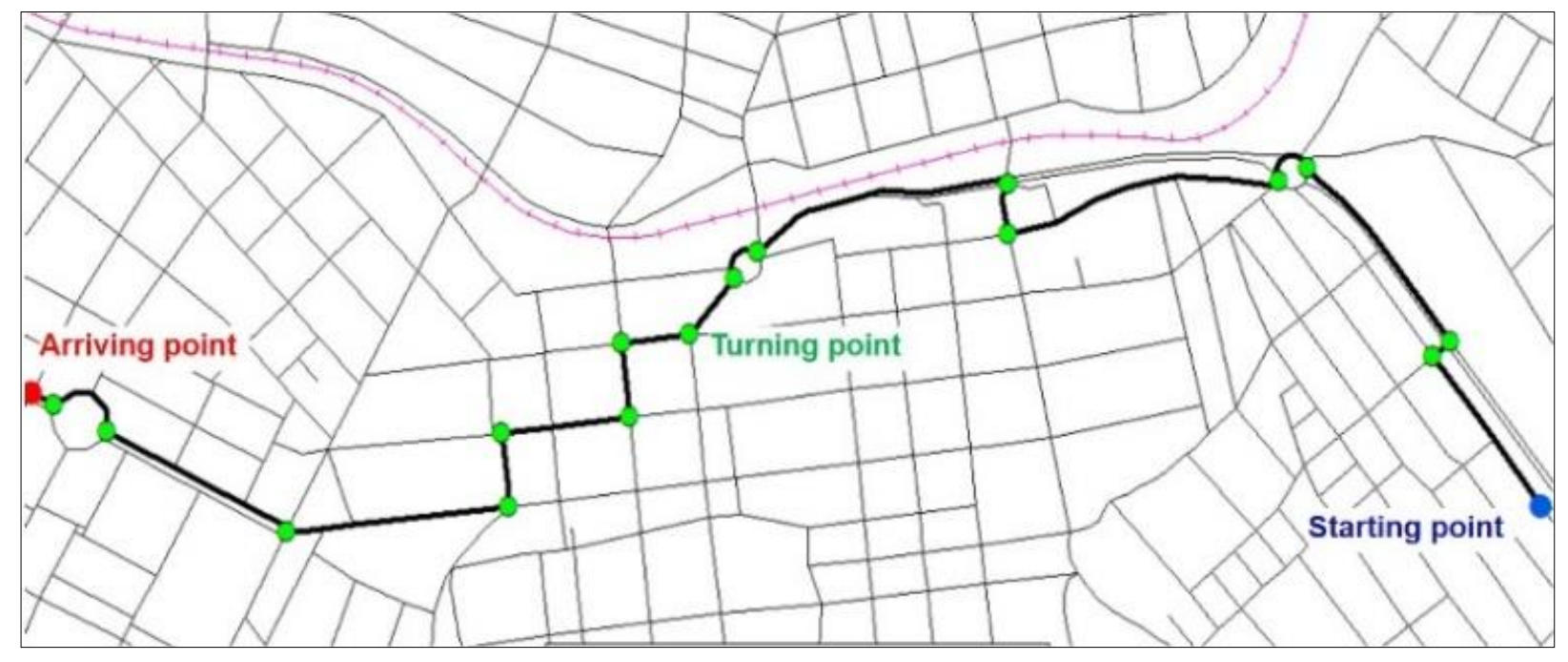

Figure 3: The study area and the experimental route. 
To ensure the maps showed various types of urban road, the experimental route was selected considering the location of the roads (e.g., residential or central), the complexity of the maneuver (e.g., simple or complex) and the physical properties of the roads (width, length, etc.) as pointed out by Pugliesi, Decanini and Tachibana (2009). The drivers in the experiment had little knowledge of the study area. The attributes of each of the 13 maneuvers on the experimental route are shown in Table 2.

Table 2: Attributes of maneuvers on the experimental route.

\begin{tabular}{cccc}
\hline $\begin{array}{c}\text { Number of } \\
\text { maneuver }\end{array}$ & $\begin{array}{c}\text { Decision } \\
\text { point }\end{array}$ & $\begin{array}{c}\text { Navigation } \\
\text { guidance }\end{array}$ & $\begin{array}{c}\text { Complexity } \\
\text { of maneuver }\end{array}$ \\
\hline M1 & Intersection & Right turn & Simple \\
M2 & Intersection & Left turn & Simple \\
M3 & Roundabout - 7 choices & 4th exit & Complex \\
M4 & Intersection & Right turn & Simple \\
M5 & Intersection & Right turn and Left Immediately & Complex \\
M6 & Roundabout - 5 choices & 3rd exit & Complex \\
M7 & Intersection & Right turn & Simple \\
M8 & Intersection & Left turn & Simple \\
M9 & Intersection & Right turn & Simple \\
M10 & Intersection & Left turn & Simple \\
M11 & Intersection & Right turn & Simple \\
M12 & Intersection & Right turn and Immediately left turn & Complex \\
M13 & Roundabout - 4 choices & 2nd exit & Complex \\
\hline
\end{tabular}

\subsubsection{Display size and Map scale}

A 7-inch LCD screen (1024 x 768) was chosen to display the RGNS maps. The size and resolution were determined to accord with what has been adopted for RGNS models in Brazil (Ramos et al. 2014a).

Two different map scales were adopted, 1:3,000 and 1:6,000. These display sizes were chosen because a scale larger than 1:3,000 did not assist drivers in the preview stage because they not could form a mental image of the maneuver layout, however the use of a scale map smaller than 1:6,000 did not help the drivers in the identification stage because the maneuver's legibility was reduced on the map. According to the model proposed by Ross and Burnett (2001), five different stages are involved when following a route task: preview, identification, confirmation, trust, and orientation. Ramos et al. (2016) argue that maps should be made with a proper visual balance, which includes decision about scale selection, so that it can support the driver at each stage of following a route task.

It is important to emphasize that the two scales $(1: 3,000$ and 1:6,000) were determined based on both approaches applied by Ramos et al. (2016) and their results related to driver preference for RGNS map scale. These authors point out that, as well as the media size and type of information required by the driver at each different stage of the navigation task, the driver's preference is another important issue that should be considered when map scale is determined for RGNS maps. 


\subsubsection{Selection and organization of information elements}

To support the navigation task, a set of elements was selected for maps at different scales. According to the literature review (Burnett 1998, May, Ross and Bayer 2003) RGNS maps should present: route (to show the way the driver should follow to his destination), car (to identity the driver's location along the route), direction arrow (to instruct the driver where to turn) and road network along with its name. In our approach, roads were divided into main and secondary roads and show a railroad element because it crosses the study area. The railroad was selected in the RGNS maps to provide spatial context for drivers. The visual hierarchy of the map elements was determined according to the navigation tasks (Table 3). The direction arrow was presented only for tactical tasks. To indicate the beginning of a tactical task, a beep was generated by the RGNS when the car was located 100 meters before the maneuver. This distance was chosen based on previous works such as Pugliesi, Decanini and Tachibana (2009) and Marques, Decanini and Pugliesi (2012). A total of 13 beeps were presented along the route, one before each maneuver.

Table 3: Hierarchy of the information elements.

\begin{tabular}{|c|c|c|c|c|c|}
\hline Information & Category & Geometry & Hierarchy & (RGB) & Symbol \\
\hline Car & Theme & Point & $1 s t$ & $(255,0,0)$ & \\
\hline Direction arrow & Theme & Point & $1 s t$ & $(0,255,0)$ & \\
\hline Route & Theme & Line & 2nd & $\begin{array}{c}(0,0,0) \\
(255,166,0)\end{array}$ & \\
\hline Road network & Base Map & Line & $3 r d$ & $\begin{array}{c}(255,255,255) \\
(0,0,0)\end{array}$ & — $^{*} *$ \\
\hline Blocks & Base Map & Polygon & 4 th & $\begin{array}{c}\text { Full: }(240,240, \\
240) \\
\text { Outline: }(255, \\
255,255)\end{array}$ & \\
\hline Railroad & Base Map & Line & 4th & $(230,0,200)$ & $\rightarrow \bullet \mapsto$ \\
\hline Annotation & Base Map & Point & 4 th & $(0,0,0)$ & \\
\hline
\end{tabular}

*Symbol of secondary road for map in 1:3,000 scale.

$* *$ Symbol of secondary road for map in 1:6,000 scale.

\subsubsection{Graphic design of maps}

The graphic design of maps of two different scales $(1: 3,000$ and 1:6,000) was based on perceptive grouping and figure-ground segregation as noted by MacEachren (1995), Dent, Torguson and Hodler (2009) and Slocum et al. (2009). Additionally, the results of Ramos et al. (2014b) relating to driver preference for the color of the route and direction arrow were adopted. The graphic design of the map elements is shown in Table 3.

Maps were designed in heads-up orientation (egocentric view) and orthogonal view (2D maps). For heads-up orientation the car is fixed in the center of the map, and the map display is rotated around the static car symbol. Although navigation system manufacturers allow drivers to choose 
between navigation displays with an orthogonal or perspective view (3D map), 3D maps are associated with a higher visual demand than 2D ones (Lin. Wu and Chien 2010).

\subsection{Map making}

Maps of 1:3,000 and 1:6,000 scales were derived from an accurate cartographic database at a scale of $1: 1,000$ by applying generalization techniques. All maps were constructed using ArcGIS software. A total of seven generalization operations were applied to making maps of different scales: selection, collapse, exaggeration, displacement, aggregation, symbolization and abbreviation (Shea and McMaster 1992).

The collapse operation allowed a reduction of the amount of detail displayed on the 1:6,000 scale maps. Exaggeration was useful to maintain the clarity of main road and route shape despite the scale reduction. The exaggeration of the route size on the map might allow drivers to more easily identify their location in the road network. The displacement operation was used to counteract problems arising when two or more map elements were in conflict due to proximity, such as railroad and route. The aggregation operation was applied to maintain the legibility of the direction arrow when coalescence occurred between it and other map elements due to scale reduction. The symbolization operation was applied to enhance legibility of the map in view of the scale reduction. The abbreviation operation was applied to omit the names of main or secondary roads not directly linked to the experimental route. Figures 4 to 10 show the generalization process of maps. The visual demand, navigational error and satisfaction level were evaluated for maps given in 1:3,000 or 1:6,000 scale and they show simple (Figure 9) and complex maneuvers (Figure 10).

(a)

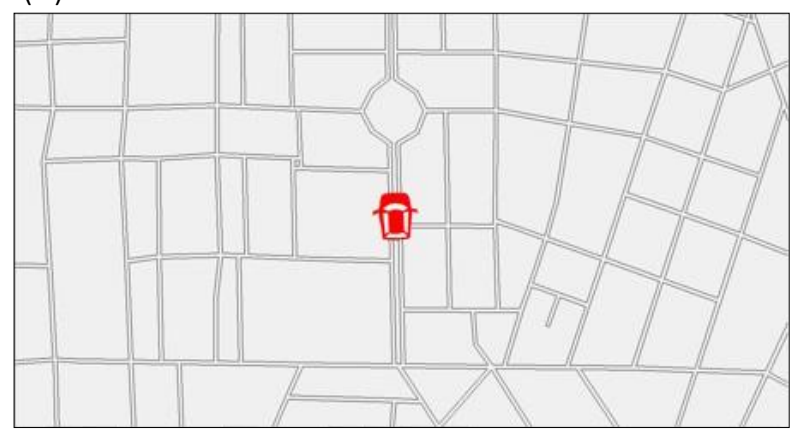

Figure 4: Map of 1:6,000 scale before (a) and after (b) application of collapse operator on road network.

(a)

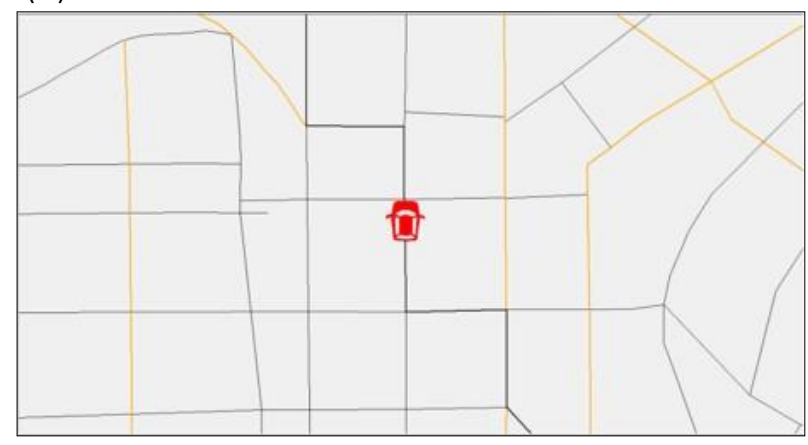

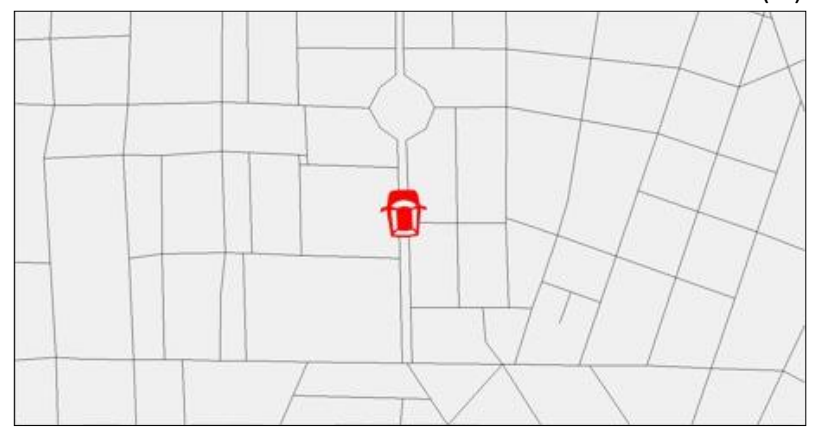

\section{.}


(a)

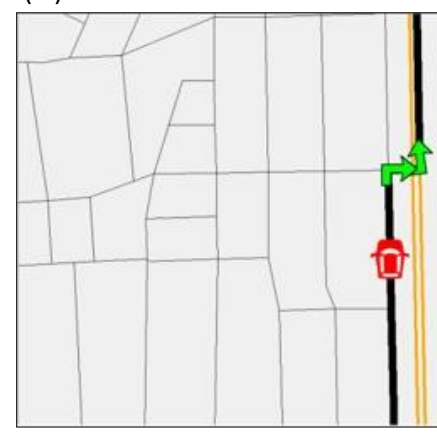

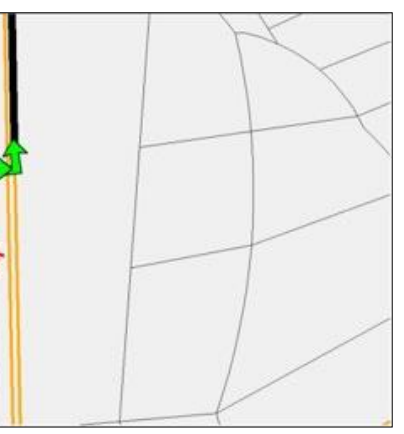

(b)

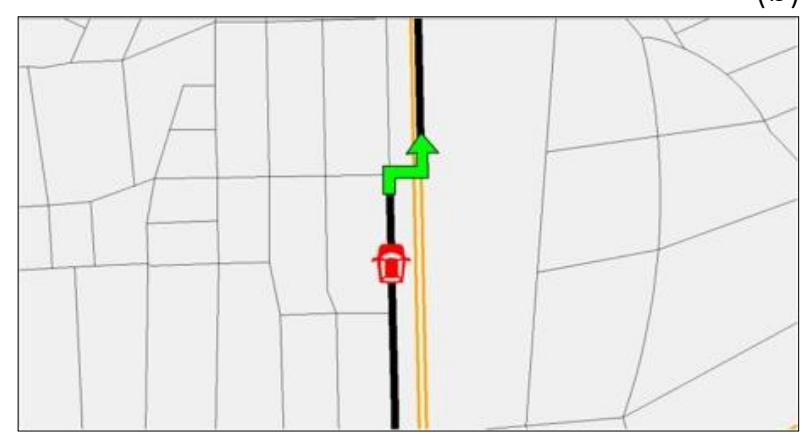

Figure 6: Map of 1:6,000 scale before (a) and after (b) application of aggregation and symbolization operators on direction arrow.

(a)

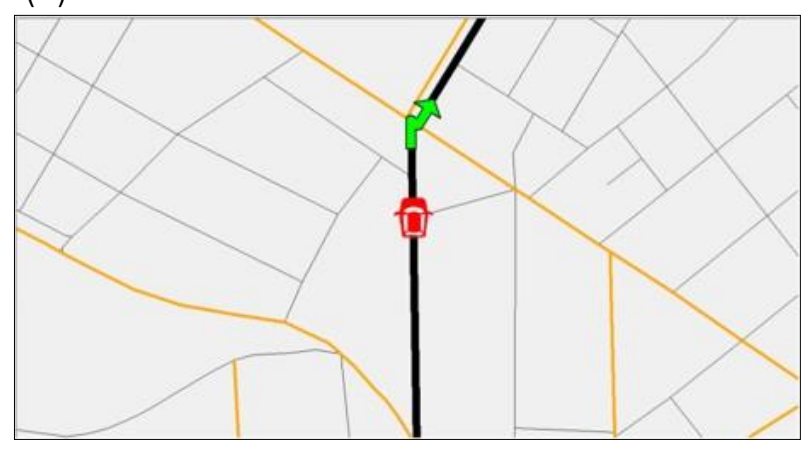

(b)

Figure 7: Map of 1:6,000 scale before (a) and after (b) application of symbolization operator on direction arrow.

(a)

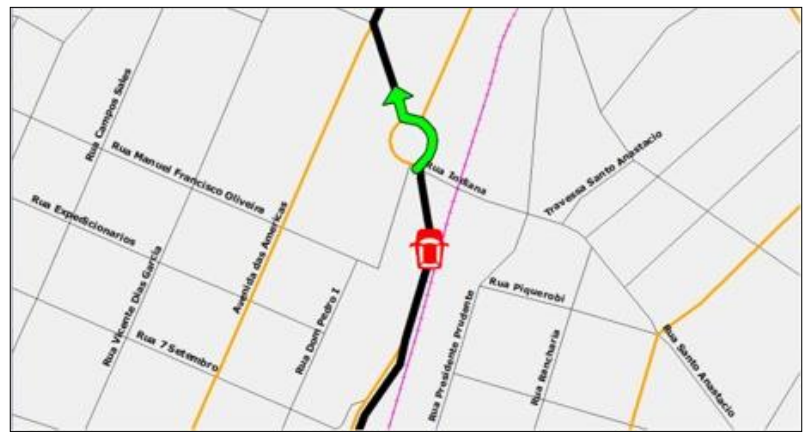

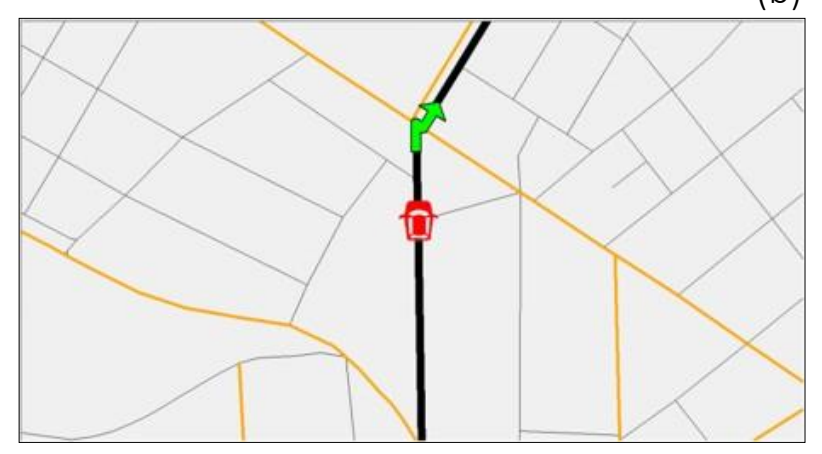

Figure 8: Map of 1:6,000 scale before (a) and after (b) application of abbreviation and displacement operators on annotation and railroad respectively.

(a)

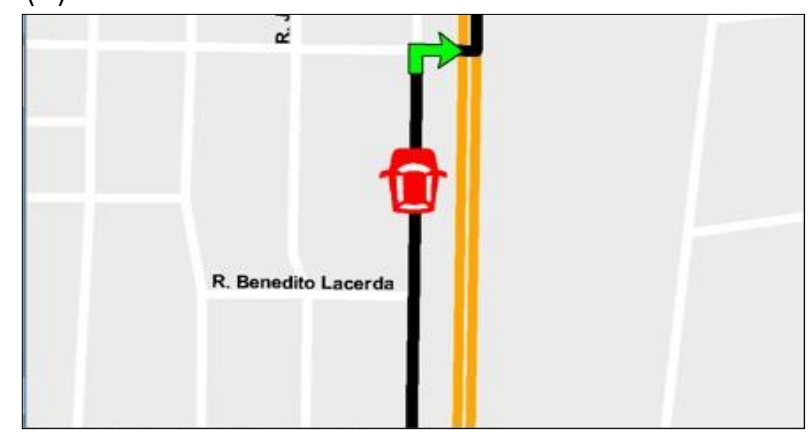

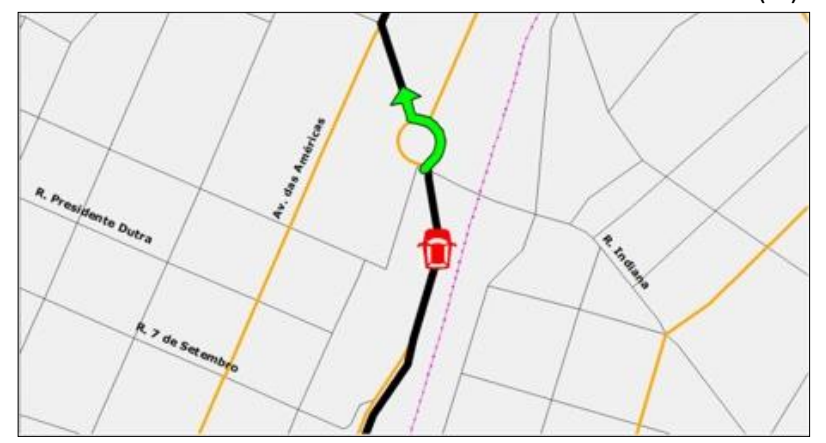

(b)

Figure 9: Map representing simple maneuver in scale 1:3,000 (a) and 1:6,000 (b). 
(a)

(b)

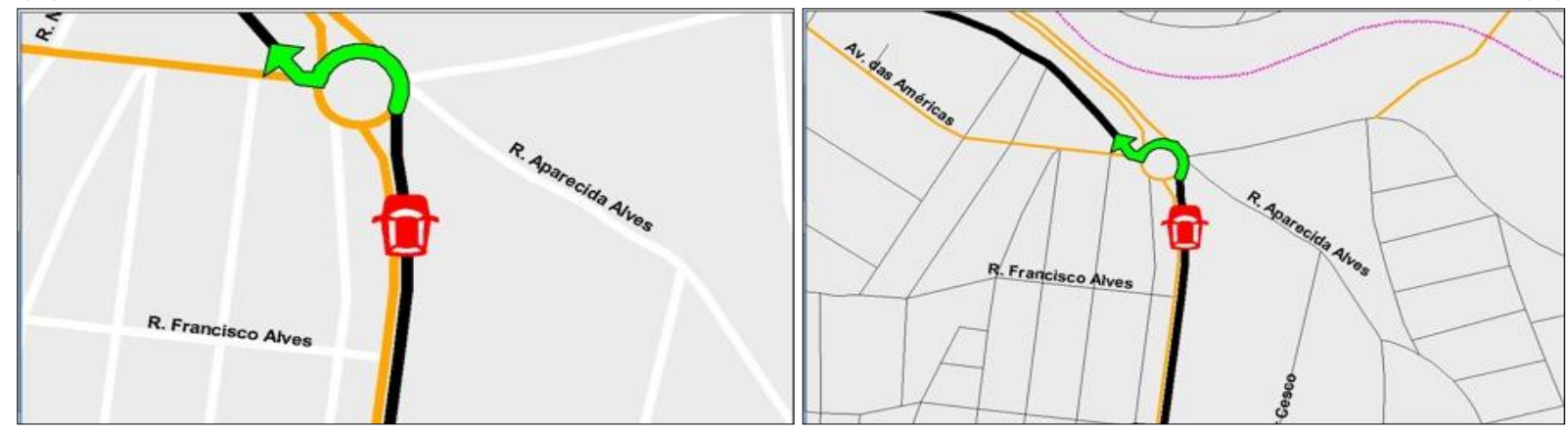

Figure 10: Map representing complex maneuver in scale 1:3,000 (a) and 1:6,000 (b).

\subsection{Procedure of driving simulation task}

The subjects were divided into two equal-sized groups (group 1 and group 2). Each group consisted of 13 males and 13 females. Group 1 started the driving task using maps at the 1:3,000 scale (maneuvers 1 to 6) and finished the travel using maps at the 1:6,000 scale (maneuvers 7 to 13). Group 2 carried out the task in a different sequence, first using maps at the 1:6,000 scale (maneuvers 1 to 6 ) and then at the 1:3,000 scale (maneuvers 7 to 13). The two different sequences were adopted to present the maps across different scales to counterbalance the potential effects of the order. The experiment was applied individually and took one hour to complete. Before beginning the driving simulation task, drivers completed the questionnaire for individual characterization and the spatial ability test (PT/SOT). Drivers were also asked to sign a consent form, and familiarize themselves with the simulator, map scales and beep. To achieve this, the experimenter explained how the beep worked and presented examples using visual maps of different scales.

For the driving simulation task, drivers were asked to assume they would be taking a journey by car in an unknown town using an RGNS that presents maps at different scales. Drivers were also advised to pay the necessary attention to the video movie to avoid traffic accidents and to look at the navigation display by taking quick glances to get map information, preferably after the beep. To increase attention to the test and collect information about navigation errors, drivers were instructed, after hearing the beep, to verbalize the maneuver direction as understood from the map. During the driving simulation task, all navigation errors were recorded by the experimenter watching each subject. A similar procedure to collect navigational errors is found in Lin, Wu and Chien (2010) and Ramos et al. (2014c). Finally, after the driver had said the test could begin, the driving simulation task started. The simulation task began with the camera being turned on, then the video movie and maps of the system were started simultaneously.

After finishing the simulation, a questionnaire was applied to collect information about drivers' satisfaction (subjective preference) for the maps at the two different scales (to perform navigation task) considering the variation in maneuver complexity. The following questions were applied: "Of the scales shown $(1: 3,000$ and 1:6,000), which is your preference for performing the tactical task related to the simple maneuver, and why?"; "Of the scales shown (1:3,000 and 1:6,000), which is your preference for performing the task related to the complex maneuver, and why?"; "Of the scales shown $(1: 3,000$ and 1:6,000), which is your preference for performing the straight-ahead task, and why?"; and "Of the scales shown (1:3,000 and 1:6,000), which is your preference for 
performing the navigation task overall (tactical task and straight-ahead task) and why?". The straight-ahead task refers to maintaining a straight route segment between two maneuvers (Pugliesi, Decanini and Tachibana 2009). All driver preferences and opinions were collected using an audio recorder and questionnaire.

To quantify preference data, the frequency observed $\left(F_{0}\right)$ was used. Preference data refer to drivers' satisfaction for driving using the maps at 1:3,000 or 1:6,000 scale to perform maneuvers with variation in complexity, which were classified into simplex and complex one. The Chi-Square test $\left(\chi^{2}\right)$ was used for groups with $F_{0}$ equal or higher than five elements, by considering two unrelated samples. Friedman's test was applied to analyze groups with $F_{0}$ smaller than five elements, considering three related samples. In addition, trends were considered for the results when not statistically significant.

\subsection{Dependent and independent variables}

Dependent variables consist of visual demand, navigational error and map preference between the two different scales. These variables relate to subjective (driver preference) and objective (navigational error and visual demand) measures adopted to quantifying the mental workload of drivers and so evaluate the usability of RGNS interfaces. Independent variables are factors related to group characteristics (i.e. gender) and complexity of maneuver (simple versus complex).

The visual demand was quantified in terms of the four elements (variables): the number of glances, the minimum and maximum duration of glances, and the total glance duration. The number of glances refers to the number of times the driver looked at the display to complete a task (Tsimhoni, Yoo and Green 1999). Duration of glance includes the time from the moment the driver's eyes were fixed on the road, started to move to the display, and then returned to the road (Pugliesi, Decanini and Tachibana 2009). The minimum and maximum duration of glances refers to the shortest and longest time a driver required to get information from a visual interface (Tsimhoni, Yoo and Green 1999, Pugliesi, Decanini and Tachibana 2009). The total glance duration is the amount of time spent with eyes off the road during a tactical task (Pugliesi, Decanini and Tachibana 2009). High values of visual demand at the RGNS display was associated with high levels of distraction, with a potentially negative impact on driving safety. Hence the number of glances and glance duration (minimum, maximum and total) were adopted as key indicators of driving distraction.

The dependent variable for navigational error is directional error. Navigation errors were defined as situations where a subject verbalized a wrong direction for the maneuver or missed the maneuver while performing the driving simulation task, as in the approaches of Lin, Wu and Chien (2010) and Ramos et al. (2016). Finally, a questionnaire was applied to collect information about drivers' satisfaction (subjective preference) for the maps at the two different scales (to perform navigation task) considering the variation in maneuver complexity. 


\subsection{Data extraction and statistical analysis}

The visual demand data were extracted using a manual video frame capture with Microsoft Windows Movie Maker. The replay speed was set at 1/30 of the normal speed. Because tactical task time is influenced by traffic conditions and road feature, the analysis and comparison of visual demand between different maneuvers was focused on the shortest tactical task time, which corresponded to 11 seconds. Data were thus captured during this time span only, and calculations were performed to obtain the number of glances, the minimum and maximum duration of glances, and the total glance duration. All data about visual demand is in seconds. The navigational error and driver preference data were extracted from both the questionnaire and the video frame capture.

Data were processed using SPSS 16.0 (Statistical Package for the Social Sciences Software) for a confidence level of $90 \%$ or better. To analyze the quantitative data set (visual demand and navigational error), the statistical analysis was initiated applying the Shapiro Wilk normality test which indicated that not all the data followed a normal probability distribution. Therefore, as recommend by Conover (1999), to perform statistical analyses considering data without normal distribution, we adopted non-parametric tests, such as the Wilcoxon and Mann-Whitney test. We adopted parametric tests, such as the Paired-Samples T test and Independent-Samples T test to perform statistical analyses considering data with normal distribution. To analyze the qualitative data set (drivers' preference), the Chi-squared $\left(\square^{2}\right)$ test for two independent samples or the Binomial test were applied, as suggested by Conover (1999). It's should be highlighted that in all analysis we stated that the null hypothesis is "there is no difference between evaluated groups" and the alternative hypothesis is "there is significative difference between groups". Moreover, the Wilcoxon test were applied to compare two paired groups to evaluate the influences of intrasubject factors concerning maneuver complexity and map scale size on the visual demand (in seconds) on the driver. On the other hand, the Mann-Whitney test were applied to compare two independent groups and evaluate the influence of drivers' gender and visual demand.

\section{Results and Discussion}

\subsection{Visual Demand}

To determine the efficiency of maps designed at different scales (1:3,000 and 1:6,000), we initially compared the visual demand (number of glances, and minimum, maximum and total duration of glances) for each cartographic representation considering three different situations: all 13 maneuvers of the experimental route, simple maneuvers only (total of 8) and complex maneuvers of the route (total of 5). The results (Table 4) show that, regardless of the maneuver complexity, drivers look more often (number of glances) ( $p$-value $=0.014$ ) and spend much more time with eyes off the road during the tactical task (total duration of glances) ( $p$-value $<0.0001$ ) when they navigate supported by a more detailed map $(1: 3,000)$ than a more generalized one $(1: 6,000)$. The results also show that maneuver complexity is another factor influencing the visual demand on drivers. According to Table 4, to perform complex maneuvers (e.g.: roundabout), drivers not only look less often (number of glances) ( $p$-value $<0.0001$ ) to a more generalized map $(1: 6,000)$, but also for a shorter period (minimum duration of glances) ( $p$-value $<0.0001$ ) compared to a more 
detailed map $(1: 3,000)$. Additionally, a greater time (maximum duration of glances) ( $\mathrm{p}$-value $=$ $0.033)$ is required by drivers to get information from a more detailed representation $(1: 3,000)$ and much more time is consequently spent with eyes off the road during a tactical task (total duration of glances) ( $p$-value $=0.030$ ).

Table 4: Statistical description of the influence of maneuver complexity and map scale size on the visual demand on the driver.

\begin{tabular}{|c|c|c|c|c|c|}
\hline \multirow{3}{*}{ Case analyzed } & \multicolumn{5}{|c|}{ Visual demand: Number of glances } \\
\hline & \multicolumn{4}{|c|}{ Wilcoxon (rank means): First \& second } & \multirow{2}{*}{ Map scale more efficient } \\
\hline & Map_1:3,000 & Map_1:6,000 & Z & $\mathrm{p}$-Value & \\
\hline All maneuvers & 20.13 & 28.79 & 2.462 & 0.014 & $1: 6,000$ \\
\hline Simple maneuvers & 24.78 & 27.00 & 0.874 & 0.382 & - \\
\hline \multirow{3}{*}{ Complex maneuvers } & \multicolumn{4}{|c|}{ Paired-Samples T test (Map_1:3,000 \& Map_1:6,000) } & \multirow{3}{*}{ More efficient map scale } \\
\hline & Mean & Standard & $\mathrm{t}$ & p-Value & \\
\hline & $3.22 \& 2.67$ & $0.955 \& 0.871$ & 4.437 & $<0.0001$ & \\
\hline \multirow{3}{*}{ Case analyzed } & Visual dem & d: Minimum du & tion of $g$ & ances & \multirow{3}{*}{ More efficient map scale } \\
\hline & Wilcoxc & (rank means): $\mathrm{F}$ & t \& secc & & \\
\hline & Map_1:3,000 & Map_1:6,000 & Z & p-Value & \\
\hline \multirow{2}{*}{$\begin{array}{l}\text { All maneuvers } \\
\text { Simple maneuvers } \\
\text { only }\end{array}$} & 28.48 & 22.73 & - & 0.126 & - \\
\hline & 23.08 & 31.55 & 0.241 & 0.809 & - \\
\hline Complex maneuvers & 15.80 & 30.84 & 4.117 & $<0.0001$ & $1: 6,000$ \\
\hline \multirow{3}{*}{ Case analyzed } & \multicolumn{4}{|c|}{ Visual demand: Maximum duration of glances } & \multirow{3}{*}{ More efficient map scale } \\
\hline & \multicolumn{4}{|c|}{ Wilcoxon (rank means): First \& second } & \\
\hline & Map_1:3,000 & Map_1:6,000 & Z & p-Value & \\
\hline \multirow{2}{*}{$\begin{array}{l}\text { All maneuvers } \\
\text { Simple maneuvers } \\
\text { only }\end{array}$} & 27.33 & 25.07 & - & 0.404 & - \\
\hline & 30.13 & 22.66 & $\begin{array}{c}- \\
0.628\end{array}$ & 0.530 & - \\
\hline Complex maneuvers & 24.22 & 26.97 & 2.218 & 0.033 & $1: 6,000$ \\
\hline \multirow{3}{*}{ Case analyzed } & \multicolumn{4}{|c|}{ Visual demand: Total glance duration } & \multirow{3}{*}{ More efficient map scale } \\
\hline & \multicolumn{4}{|c|}{ Wilcoxon (rank means): First \& second } & \\
\hline & Map_1:3,000 & Map_1:6,000 & Z & $p$-Value & \\
\hline All maneuvers & 22.48 & 31.19 & 0.542 & 0.588 & - \\
\hline Simple maneuvers & 18.43 & 29.15 & 3.623 & $<0.0001$ & $1: 6,000$ \\
\hline \multirow{3}{*}{ Complex maneuvers } & Paired-Sample & test (Map_1:3, & $0 \& \mathrm{Ma}$ & $=1: 6,000)$ & \multirow{2}{*}{ More efficient map scale } \\
\hline & Mean & Standard & $\mathrm{t}$ & $p$-Value & \\
\hline & $3.55 \& 3.20$ & $1.11 \& 1.07$ & 2.230 & 0.030 & $1: 6,000$ \\
\hline
\end{tabular}


Based on the case studies, we can state that both map scale and maneuver complexity variation are factors that contribute to distraction for drivers and affect driving safety. If, on the one hand, maps at different scales $(1: 3,000$ and 1:6,000) are equally efficient in assisting in simple maneuver execution (e.g.: turn right, turn left), on the other hand, more generalized maps $(1: 6,000)$ require less visual demand when drivers perform complex maneuvers (e.g.: take 3rd exit on the roundabout).

A more detailed analysis (Figure 11) was carried out for each component of the visual demand (number of glances, minimum, maximum and total glance duration) based on thresholds for visual demand recommended by the literature. We adopted the mean distribution of visual demand according to map scale and maneuver complexity variation for this analysis. According to Green (1999), to navigate using an RGNS, the recommended number of glances is a maximum of four glances during a task (e.g.: tactical task). We can therefore state that the level of detail defined in both navigation maps $(1: 3,000$ and $1: 6,000)$ is appropriate as the average of the number of glances is below of the threshold in each analysis (Figure 11). The number of glances is associated with the visual search process, so a high number of glances suggests problems in the interface design (Goldberg and Kotval 1999).

In additional, we can also infer that both cartographic representations are efficient in terms of the amount of time drivers spend with their eyes off the road during a tactical task (Figure 11). The suggested threshold is 8 seconds (Jama 2004); we found a total duration of glances no higher than 4.5 seconds regardless maneuver complexity or map scale variation. Total duration of glances is an important variable in quantifying visual demand as it specifically enables identification of both the amount of time drivers spend with their eyes off the road and performing tactical tasks related to simple or complex maneuvers (Pugliesi et al. 2013).

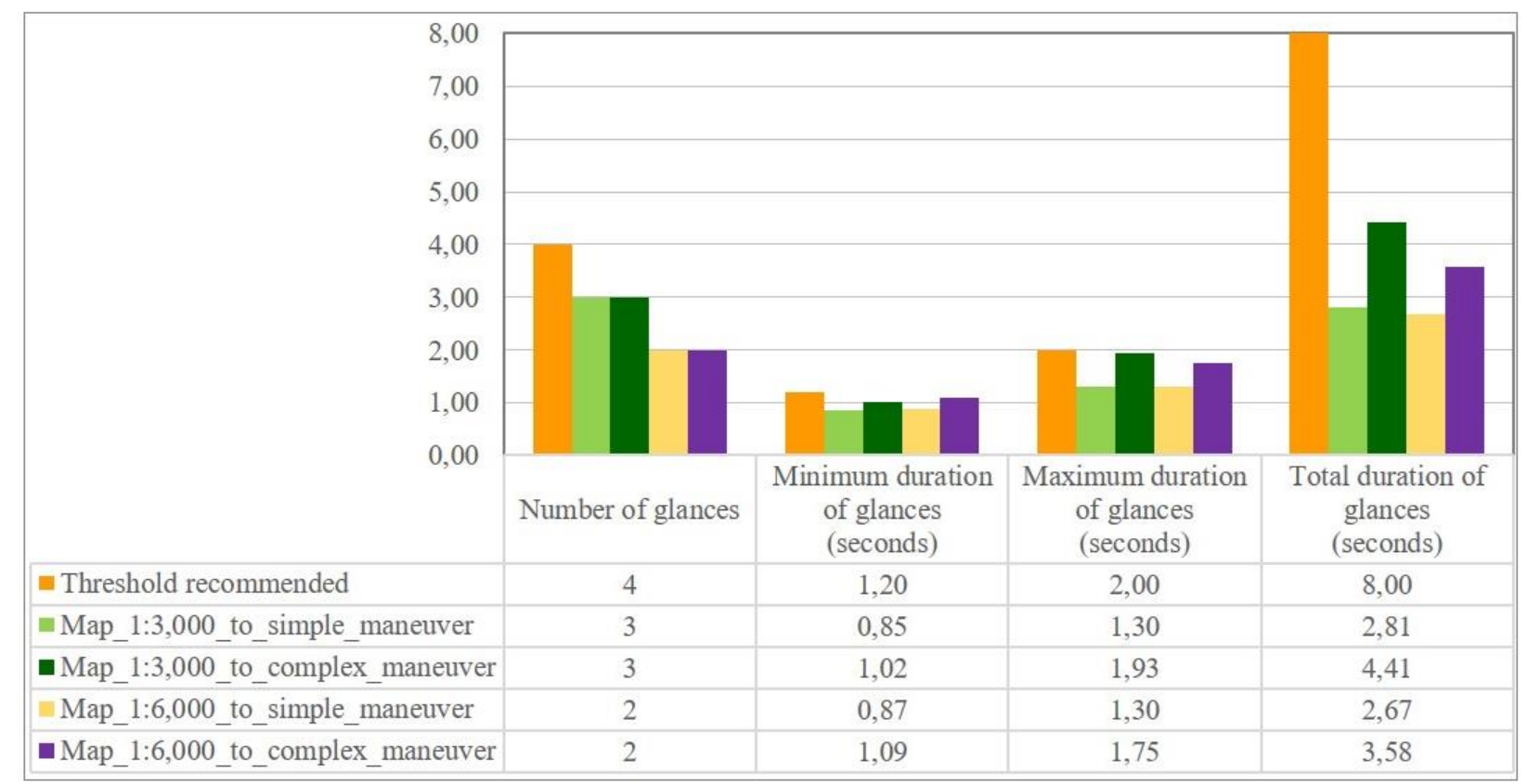

Figure 11: Comparation of mean distribution of the visual demand in relation to map scale and maneuver complexity variation with threshold recommended.

For minimum and maximum duration of glances, the recommended thresholds are 1.2 and 2.0 seconds, respectively (Green 1999, Wikman, Nieminen and Summala 1998, Nhtsa 2012) to read an interface while driving a vehicle. We would therefore stress that navigation maps designed at 
the two different scales $(1: 3,000$ and 1:6,000) are equally efficient in terms of duration of glances (minimum and maximum). As Figure 11 shows, the visual demand was below the recommended thresholds for all analysis situations. Duration of glances (minimum and maximum) is associated with the processing time required to read an interface (Poole and Ball 2005). Glances of long duration are associated with complex interfaces, as it is assumed the less time is required for reading map, the more efficient is the interface design (Wikman, Nieminen and Summala 1998; Poole and Ball 2005). Lavie and Oron-Gilad (2013) argue that high-performance navigation maps have important implications for the usability of RGNS, because, if drivers can easily comprehend information on a map, they can make decisions quickly during driving tasks.

According to the literature review (Wikman, Nieminen and Summala 1998, Labiale 2001; ChingTorng, Hsin-Chieh and Ting-Yen 2010, Pugliesi, Decanini and Tachibana 2009), the number of glances and the maximum duration of glances are two essential(s) indicators to measure the potential risk that interaction with an interface implies for traffic safety. Ching-Torng, Hsin-Chieh and Ting-Yen (2010) point out that an interface requiring many glances and a lengthy duration of glances indicates a high level of distraction for drivers. The Japanese Automobile Manufacturers Association (Jama 2004) says that a navigation interface should enable drivers to get information with a few glances and in as short a period as possible to minimize the negative impact on traffic safety. Based on the cases we investigated, we can argue that audio-dynamic maps designed at two different scales $(1: 3,000$ and 1:6,000) are efficient in terms of traffic safety in heading-up orientation. However, it should be remembered that higher levels of distraction were associated with maps that are more detailed, especially when drivers were performing complex maneuvers (Figure 11).

\subsubsection{Visual demand and influence on group characteristics}

Table 5 presents the visual demand results in relation to drivers' gender. We found that women need to look at maps more frequently than men to perform simple maneuvers, regardless of map scale, whether $1: 3,000$ ( $p$-value $=0.008)$ or 1:6,000 ( $p$-value $=0.071)$. However, no relation was found between drivers' gender and visual demand in the case of complex maneuvers (Table 5). These results corroborate a previous study by Ramos et al (2015) about the correlation between gender and visual demand on drivers. The higher visual demand on women in terms of number of glances reflects their higher spatial anxiety compared to men when navigating using maps. Lawton (1994) argues that spatial anxiety, or "fear of becoming lost", is a feeling that happens when someone is navigating in an unfamiliar area.

Studies show that women use strategies different from men when navigating in an unknown area (Dabbs et al. 1998, Tsimhoni, Yoo and Green 1999, Coluccia and Louse 2004, Wu et al. 2013), and that women tend to show higher levels of spatial anxiety when performing the same tasks as men (Lawton 1994, Coluccia, Louse and Brandimonte 2007). One reason for this is due to women having less spatial ability than men (Dabbs et al. 1998, Coluccia, Louse and Brandimonte 2007). The results of our spatial ability test (Table 6) corroborate this literature discussion. We found that men showed better performance not only in estimating correct direction to target (absolute directional error) ( $p$-value $=0.006$ ) but also when answering a greater number of questions ( $p$ value $=0.010$ ). Hooven et al. (2004) say that spatial ability is largely influenced by an individual's testosterone level. 
Table 5: The relationship of drivers' gender and visual demand.

\begin{tabular}{|c|c|c|c|c|c|}
\hline \multirow{3}{*}{$\begin{array}{l}\text { Case analyzed: } \\
\text { Map scale 1:3,000 }\end{array}$} & \multirow{3}{*}{$\begin{array}{c}\text { Visual demand } \\
\text { variables (glances) }\end{array}$} & \multicolumn{4}{|c|}{ Mann-Whitney test (ranks mean) } \\
\hline & & \multicolumn{2}{|c|}{ Gender } & \multirow[t]{2}{*}{ Z } & \multirow[t]{2}{*}{$p$-Value } \\
\hline & & Male & Female & & \\
\hline \multirow{4}{*}{ Simple maneuver } & Number & 20.94 & 32.06 & 2.656 & 0.008 \\
\hline & Minimum duration & 29.71 & 23.29 & -1.533 & 0.125 \\
\hline & Maximum duration & 27.77 & 25.23 & -0.604 & 0.546 \\
\hline & Total glance duration & 23.44 & 29.56 & -1.455 & 0.146 \\
\hline \multirow{6}{*}{ Complex maneuver } & Minimum duration & 24.46 & 28.54 & -0.971 & 0.331 \\
\hline & Maximum duration & 26.40 & 26.60 & -0.046 & 0.963 \\
\hline & \multirow{3}{*}{$\begin{array}{l}\text { Number of glances } \\
\text { (males } x \text { females) }\end{array}$} & \multicolumn{4}{|c|}{ Independent-Samples T test } \\
\hline & & Mean & $\begin{array}{l}\text { Standard } \\
\text { Deviation }\end{array}$ & $\mathrm{t}$ & p-Value \\
\hline & & $3.09 \times 3.35$ & $1.075 \times 0.820$ & 0.965 & 0.339 \\
\hline & $\begin{array}{l}\text { Total glance duration } \\
\text { (males } \times \text { females) }\end{array}$ & $4.26 \times 4.55$ & $1.32 \times 1.42$ & -0.78 & 0.436 \\
\hline \multirow{3}{*}{$\begin{array}{l}\text { Case of analyzed: } \\
\text { Map scale 1:6,000 }\end{array}$} & \multirow{3}{*}{$\begin{array}{c}\text { Visual demand } \\
\text { variables (glances) }\end{array}$} & \multicolumn{4}{|c|}{ Mann-Whitney test (ranks mean) } \\
\hline & & \multicolumn{2}{|c|}{ Gender } & Z & $p$-Value \\
\hline & & Male & Female & & \\
\hline \multirow{4}{*}{ Simple maneuver } & Number of glances & 22.79 & 30.21 & 1.807 & 0.071 \\
\hline & Minimum duration & 27.75 & 25.25 & -0.596 & 0.551 \\
\hline & Maximum duration & 26.52 & 26.48 & 0.009 & 0.993 \\
\hline & Total glance duration & 23.92 & 29.08 & 1.226 & 0.220 \\
\hline \multirow{6}{*}{ Complex maneuver } & Minimum duration & 24.71 & 28.29 & 0.852 & 0.694 \\
\hline & Maximum duration & 29.69 & 23.31 & -1.520 & 0.129 \\
\hline & Total glance duration & 27.35 & 25.65 & -0.403 & 0.687 \\
\hline & Number of glances & \multicolumn{4}{|c|}{ Independent-Samples T test } \\
\hline & (males $x$ females) & Mean & Standard & $\mathrm{t}$ & p-Value \\
\hline & & $2.67 \times 2.67$ & $0.939 \times 0.817$ & 0.250 & 0.980 \\
\hline
\end{tabular}

*Significant at $p$-Value $\leq 0.10$. *Significant at $p$-Value $\leq 0$. It means that the null hypothesis is rejected.

**The null hypothesis is "there is no relationship between the drivers' gender and the visual demand" and the alternative hypothesis is "there is significative relationship between visual demand and drivers' gender".

Table 6: The relationship of drivers' gender and spatial ability.

\begin{tabular}{|c|c|c|c|c|c|c|}
\hline \multirow{3}{*}{$\begin{array}{c}\text { Variables of Spatial } \\
\text { Orientation test PT/SOT }\end{array}$} & \multirow{2}{*}{\multicolumn{2}{|c|}{$\frac{\text { Descriptive statistical }}{\text { Gender }}$}} & \multicolumn{4}{|c|}{ Mann-Whitney test (ranks mean) } \\
\hline & & & \multicolumn{2}{|c|}{ Gender } & \multirow{2}{*}{ Z } & \multirow{2}{*}{$\mathrm{p}$-valor } \\
\hline & Males & Females & Males & Females & & \\
\hline $\begin{array}{c}\text { Mean absolute } \\
\text { directional error } \\
\text { (degrees) }\end{array}$ & $32.5^{\circ} \pm 31^{\circ}$ & $64.0^{\circ} \pm 53^{\circ}$ & 20.73 & 32.27 & -2.745 & 0.006 \\
\hline $\begin{array}{l}\text { Number of questions } \\
\text { answered in } 5 \text { minutes }\end{array}$ & 9 & 7 & 31,54 & 21,46 & 2,426 & 0,010 \\
\hline
\end{tabular}




\subsection{Navigation errors}

To determine the effectiveness of maps at different scales (1:3,000 and 1:6,000), we analyzed the number of navigational errors made by the 52 drivers in each of the 13 maneuvers on the experimental route while they performed the driving simulation task. This approach was based on Lin, Wu and Chien (2010) and Ramos et al. (2014c). The results (Figure 12) shows that drivers made a similar number of navigation errors, and in the same maneuvers, regardless of the map used. These findings suggest that the cartographic design applied to maps at two different scales is effective as drivers maintained a similar performance in the navigation task when maps with a distinct level of generalization assisted them.

However, it should be noted (Figure 12) that all navigation errors occurred in complex maneuvers, and, in these cases, drivers had a better performance when guided by a more detailed map $(1: 3,000)(p$-value $=0.046)$ than a more generalized one $(1: 6,000)$. We can therefore say that there is an association between navigation errors and maneuver complexity, and this issue influences drivers' performance when they navigate using an RGNS. No association was established between the number of navigation errors in complex maneuver and drivers' gender regardless the map scale, if $1: 3,000$ ( $p$-value $=0.245)$ or $1: 6,000(p$-value $=0.560)$.

According to the literature review the decision-making process is more difficult in complex maneuvers because the driver is provided with several navigation choices (Labiale 2001; Pugliesi, Decanini and Tachibana 2009). Our results corroborate this discussion since drivers made mistakes at all three roundabouts (M3, M6 and M13) of the experimental route, and the more exits there were at the junctions the greater the number of errors. Kaber et al. (2012) concluded in their research that the more exposed drivers were to situations of cognitive overload, the higher is the tendency for them to make mistakes in driving tasks. The literature (Dingus and Hulse 1993, Young and Stanton 2005, 2006) explain that the reduction of performance in the main task (i.e.: driving a car) is a way in which drivers compensate for the demand required by a secondary task (e.g.: reading a navigation map).

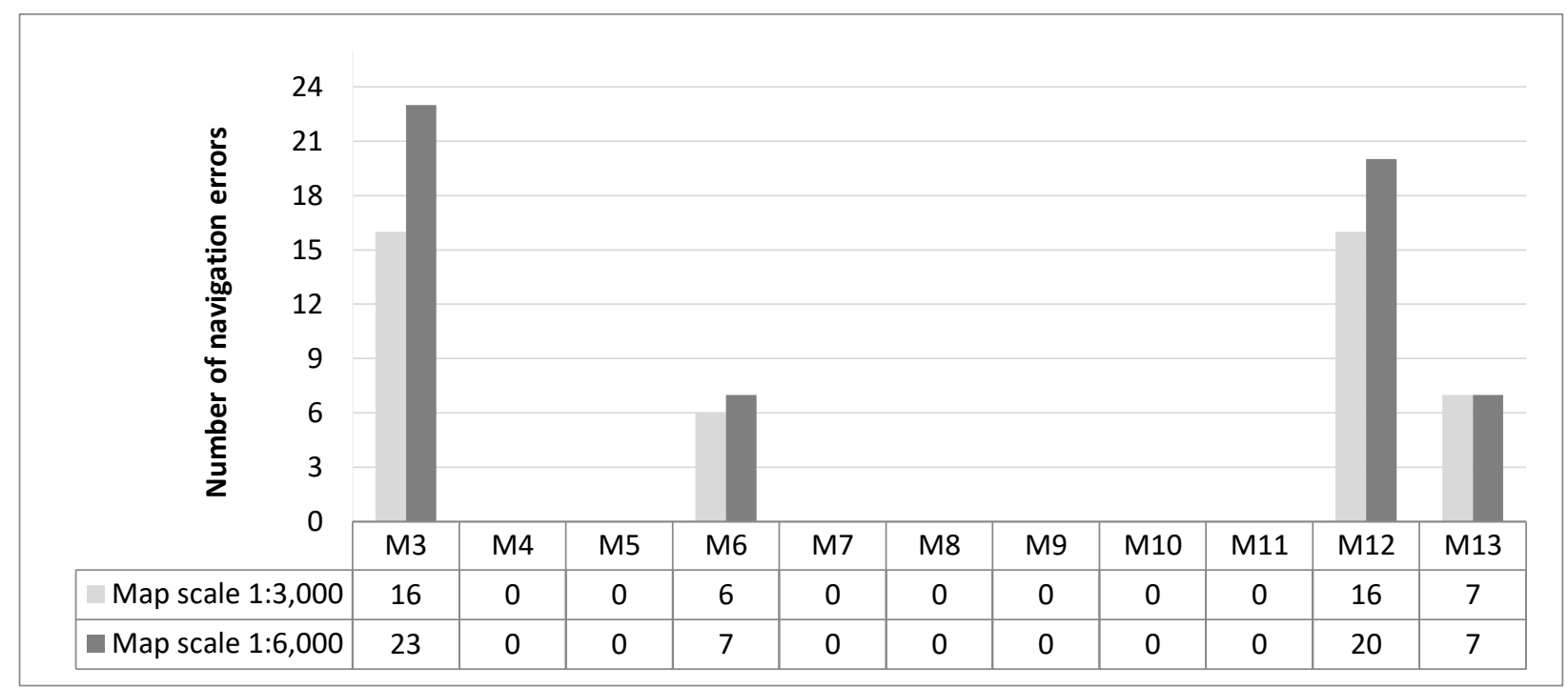

Figure 12: Error navigation distribution for each maneuver of the experimental route. 


\subsection{Drivers' satisfaction}

To determine which map scale $(1: 3,000$ or $1: 6,000)$ is preferred by drivers when carrying out the navigation task using an RGNS, we analyzed the drivers' answers for each question applied after completion of the driving simulation task. Results are presented in Table 7.

We found that drivers' satisfaction is similar for both navigation maps (scale 1:3,000 and 1:6,000) when the tactical task is related to simple maneuvers ( $p$-value $=0.782)$. However, a more detailed map $(1: 3,000$ scale) is preferred ( $p$-value $<0.0001)$ when maneuvers with a higher level of difficulty, such as a roundabout, are to be performed. According to drivers' comments, the reason is that a less generalized map supports identification of the direction of the maneuver clearly and quickly. Drivers suggested that the 1:3,000 scale map is preferable primarily for the roundabout situations as they contain multiple exits and this issue increases the difficulty of deciding about which is the correct exit.

Table 7: Frequency of drivers' satisfaction for maps at two different scales for performing a navigation task.

\begin{tabular}{|c|c|c|c|c|}
\hline \multirow[b]{2}{*}{ Questions } & \multicolumn{2}{|c|}{$\begin{array}{c}\text { Frequency of } \\
\text { drivers' satisfaction }\end{array}$} & \multicolumn{2}{|c|}{$\begin{array}{l}\text { Statistical Test for two } \\
\text { independent samples }\end{array}$} \\
\hline & $\begin{array}{l}\text { Map } \\
\text { scale } \\
1: 3,000\end{array}$ & $\begin{array}{l}\text { Map } \\
\text { scale } \\
1: 6,000\end{array}$ & Test & $p$-value \\
\hline $\begin{array}{l}\text { Of the scales shown }(1: 3,000 \text { and } 1: 6,000) \text {, } \\
\text { which is your preference when performing } \\
\text { a tactical task related to a simple maneuver, } \\
\text { and why? }\end{array}$ & 27 (52\%) & $25(48 \%)$ & $\square^{2}=0.077$ & 0.782 \\
\hline $\begin{array}{l}\text { Of the scales shown }(1: 3,000 \text { and } 1: 6,000) \text {, } \\
\text { which is your preference when performing } \\
\text { a task related to a complex maneuver, and } \\
\text { why? }\end{array}$ & $44(85 \%)$ & $8(15 \%)$ & $\square^{2}=24.923$ & $<0.0001$ \\
\hline $\begin{array}{l}\text { Of the scales shown }(1: 3,000 \text { and } 1: 6,000) \text {, } \\
\text { which is your preference when performing } \\
\text { a straight-ahead task, and why? }\end{array}$ & $3(6 \%)$ & 49 (94\%) & $\begin{array}{c}\text { Binomial } \\
\text { test }\end{array}$ & $<0.0001$ \\
\hline $\begin{array}{l}\text { Of the scales shown }(1: 3,000 \text { and } 1: 6,000) \text {, } \\
\text { which is your preference when performing } \\
\text { a navigation task overall (tactical task and } \\
\text { straight-ahead task), and why? }\end{array}$ & $16(31 \%)$ & $36(69 \%)$ & $\square^{2}=7.692$ & 0.006 \\
\hline
\end{tabular}

Conversely, we found that drivers prefer to navigate aided by a 1:6,000 scale map when they need to perform a straight-ahead task ( $p$-value $<0.0001$ ), or even have the option of fixing a cartographic scale to the overall navigation task ( $p$-value $=0.006)$. According to drivers' comments, maps at the 1:6,000 scale help not only identify the direction of the next and subsequent maneuvers, but also supply information on the surroundings along the route. Considering the model proposed by Ross 
and Burnett (2001) to explain how navigation occurs, it is interesting to note that five different stages are involved in this model: preview of the next maneuver on route, identification of the maneuver direction, confirmation of the correct exit to take, trust that the right route is being followed, and overall orientation in the route. Ramos et al. (2016) suggest that RGNS maps are more acceptable to drivers in that they support drivers at those different stages of the navigation task. Our results also corroborate these findings. No association was established between drivers' preference for map scale and group characteristics.

\section{Conclusions and recommendations}

This work evaluated the usability of audio-dynamic maps in heading-up orientation, designed at two different scales for an RGNS prototype. According to the results of the driving simulation task, we conclude that the map scale selection has an influence on the usability of these systems, and this depends on the maneuver complexity variation level. We found that the maps were equally efficient and effective in supporting tactical tasks related to simple maneuvers and that driver preference was equally shared. However, the less generalized map was more effective and received greater acceptance from drivers in assisting the execution of complex maneuvers. These findings therefore support the hypothesis of our work in which we assumed that the level of map generalization affects both driver satisfaction and performance, especially in tactical tasks related to complex maneuvers.

The visual demand tests results showed that the more detailed a navigation map is, the greater the implied level of distraction for drivers, and this issue is related to the maneuver complexity level. In addition, we found that drivers of different genders show distinct levels of visual demand due both to map scale and maneuver complexity variation, and this issue is based on individual differences in terms of spatial ability. Consequently, our findings replicate the known phenomenon of significant relationship between gender and performance in visual spatial tasks. However, it should be noted that, although both map generalization level and group characteristics influence the amount of time drivers spend with their eyes off the road to get information from the RGNS interface, the maps designed at the two different scales were classified as efficient in supporting the tactical task overall, since the required visual demand was below the thresholds suggested in all the cases analyzed.

We also found that the navigation error is dependent on maneuver complexity, especially at roundabouts. Drivers improved their performance in terms of reducing the number of navigation errors when they completed complex maneuvers aided by a less generalized map, regardless of group (female $\vee$ male) or individual characteristics (e.g.: spatial ability). We therefore recommended that maneuver complexity should be considered when selecting map scale in order to maintain the effectiveness of RGNS. In addition, we found that drivers prefer to navigate using maps that support them in the different stages of navigation tasks, these maps were those designed at 1:6,000 scale in our case studies. Based on drivers' comments, maps at this scale establish a proper relationship between the spatial information along the route and the details of the maneuver directions. These findings corroborate several other research findings which argue that drivers divide driving tasks into different levels and require distinct types of information to perform each one.

Based on our case studies, we conclude that it is possible to design maps at different levels of 
detail with a high level of usability from the integration of cartographic communication principles and drivers' requirements when driving. Therefore, these maps can minimize the mental workload of drivers as well as increasing their acceptance for RGNS even when they perform the navigation task in an unknown or little-known area. This research therefore contributes to the development of RGNS about the usability of maps presented by these interfaces and can support industries which develop this kind of system. In addition, the importance of this study about interaction with interfaces in a dynamic context, such as exist when driving a car, should be stressed for the science of Cartography. As we pointed out, there is a high association between map generalization and maneuver complexity. It is necessary to investigate whether the map usability proposed in this study is like other urban grid-like road network contexts. Drivers' performance should be analyzed considering map scale variation for different grid-like road networks.

\section{ACKNOWLEDGEMENT}

This work was supported by CNPq - Conselho Nacional de Desenvolvimento Científico e Tecnológico - under Grant number 159674/2012-3.

\section{REFERENCES}

Burnett, G. E. 1998. Turn right at the King's Head": Drivers' requirements for route guidance information. PhD Thesis. Loughborough University, United Kingdom. 341 p.

Ching-Torng, L. Hsin-Chieh, W. Ting-Yen, C. 2010. Effects of e-map format and sub-windows on driving performance and glance behavior when using an in-vehicle navigation system. International Journal of Industrial Ergonomics, 40(3), pp. 330-336.

doi: 10.1016/j.ergon.2010.01.010

Coluccia, E. Losue, G. and Brandimonte, M. A. 2007. The relationship between map drawing and spatial orientation abilities: A study of gender differences. Journal of Environmental Psychology, 27(2), pp. 135-144. doi: 10.1016/j.jenvp.2004.08.006

Coluccia, E.; Louse, G. 2004. Gender differences in spatial orientation: A review. Journal of Environmental Psychology, 24(1), pp. 329-340.

Conover, W. J. 1999. Practical nonparametric statistics. 3rd ed. New York: Wiley, 584p.

Dabbs, J. M. et al. 1998. Spatial Ability, Navigation Strategy, and Geographic Knowledge Among Men and Women. Evolution and Human Behavior, 19(1), pp. 89-98.

doi: 10.1016/S1090-5138(97)00107-4

Dent, B. D. Torguson, J. S. Hodler, T. W. 2009. Cartography: Thematic Map Design. $6^{\text {th }}$ ed. McGrawHill, Georgia, 368p.

Dingus, T. A. and Hulse, M. C. 1993. Some human factors design issues and Recommendations for automobile navigation Information systems. Transportation Research Part C, 1(2), pp. 119-131. doi: 10.1016/0968-090X(93)90009-5

Goldberg, J.H. and Kotval, X.P. 1999. Computer interface evaluation using eye movements: methods and constructs. International Journal of Industrial Ergonomics, 24(1), pp. 631-645. doi: 10.1016/S0169-8141(98)00068-7 
Green, P. 1999. Visual and task demands of driver information systems. Technical report UMTRI, University of Michigan Transportation Research Institute. 119p. Available at: <https://deepblue.lib.umich.edu/handle/2027.42/1269> [Accessed 14 July 2016].

Hegarty, M. and Waller, H. 2004. A dissociation between mental rotation and perspective-taking spatial abilities. Intelligence, 32(1), pp. 175-191. doi: 10.1016/j.intell.2003.12.001

Ho, A. and Li, Z. 2004. Design of Dynamic Map for Land Vehicle Navigation. The Cartographic Journal, 41 (3), pp. 265-270. doi: 10.1179/000870404X13896

Hooven C. A. et al. 2004. The relationship of male testosterone to components of mental rotation. Neuropsychologia, 42(1), pp. 782-790. doi: 10.1016/j.neuropsychologia.2003.11.012

Japanese Automobile Manufacturers Association - JAMA. 2004. Guidelines for in-vehicle display systems-version 3.0. 2004. Available at: <http://www.jama-english.jp> [Accessed 10 March 2016].

Kaber, D. B. et al. 2012. Driver performance effects of simultaneous visual and cognitive distraction and adaptation behavior. Transportation Research Part F., 15 (5), pp. 491-501.

doi: 10.1016/j.trf.2012.05.004

Labiale, G. 2001. Visual search and preferences concerning different types of guidance displays. Behaviour \& Information Technology, 20(3), pp.149-158. doi: 10.1080/01449290110048025

Lavie, T. Oron-Gilad, T. and Meyer, J. 2011. Aesthetics and usability of in-vehicle navigation displays. International Journal of Human-Computer Studies, 69(1), pp. 80-99.

doi: 10.1016/j.ijhcs.2010.10.002

Lavie, T. and Oron-Gilad, T. 2013. Perceptions of electronic navigation displays. Behavior \& Information Technology, 32(8), pp. 800-823.

Lawton, C. A. 1994. Gender Differences in Way-Finding Strategies: Relationship to Spatial Ability and Spatial Anxiety. Sex Roles, 30(11), pp.765-779.

doi: 10.1007/BF01544230

Lee, J. Forlizzi, J. and Hudson, S. 2008. Iterative design of MOVE: A situationally appropriate vehicle navigation system. International Journal of Human-Computer Studies, 66(1), pp.198-215.

doi: 10.1016/j.ijhcs.2007.01.004

Lin, C. T. Wu, H. C and Chien, T. Y. 2010. Effects of e-map format and sub-windows on driving performance and glance behavior when using an in-vehicle navigation system. International Journal of Industrial Ergonomics, 40(1), pp. 330-336. doi: 10.1016/j.ergon.2010.01.010

Liu, Y. C. 2001. Comparative study of the effects of auditory, visual and multimodality displays on drivers' performance in advanced traveler information systems. Ergonomics, 44 (4), pp. 425-442. doi: 10.1080/00140130010011369

Maceachren, A. M. 1995. How maps work: Representation, Visualization and Design. London: the Guilford Press, 513p.

Marques, A. P. S. Decanini, M. M. S. and Pugliesi, E. A. 2012. Sistema de Navegação e Guia de Rota áudio-dinâmico com múltiplas escalas automáticas. Brazilian Journal of Cartography, 1(64), pp. 57-68.

May, A. J. Ross, T. and Bayer, S. H. 2003. Drivers' Information Requirements when Navigating in an Urban Environment. The Journal of Navigation, 56(1), pp. 89-100.

doi: 10.1017/S0373463302002114 
Michon, J. A. 1985. A critical view of driver behavior models: what do we know, what should we do? In: Evans, L., R. S. Schwing. Human behavior and traffic safety. University of Groningen, New York: Plenum Press, pp. 485-502.

doi: 10.1007/978-1-4613-2173-6_19

National Highway Traffic Safety Administration - NHTSA. 2012. Visual-Manual NHTSA Driver Distraction Guidelines for In-Vehicle Electronic Devices. Available at:

<https://www.nhtsa.gov/Research/Human-Factors/Distraction> [Accessed 25 July 2016].

Poole, A. Ball, L. 2005. Eye Tracking in Human-Computer Interaction and Usability Research: Status and Future. In: Ghaoui, C. Encyclopedia of Human-Computer Interaction. Pennsylvania, USA: Idea Group, pp. 211-219.

Pugliesi, E. A. Decanini, M. M. S. and Tachibana, V. M. 2009. Evaluation of the Cartographic Communication Performance of a Route Guidance and Navigation System. Cartography and Geographic Information Science, 36(2), pp.193-207. doi: 10.1559/152304009788188745

Pugliesi, E. A. et al. 2013. Métodos para Avaliação da Usabilidade de Sistemas de Navegação e Guia de Rota. Brazilian Journal of Cartography, 5(65), pp. 571-589.

Pugliesi, E. A. and Decanini, M. M. S. 2009. Map or Turn-By-Turn: Which Modality do the Drivers Prefer for In-Car Route Guidance and Navigation Systems? Bulletin of Geodetic Sciences, 15(1), pp. 3-15.

Ramos, A. P. M. et al. 2014a. Escalas dos mapas de sistemas de guia de rota comercial. Brazilian Journal of Cartography, 1(66), pp. 195-207.

Ramos, A. P. M. et al. 2014b. Estudo preliminar da preferência de cor para rota e seta de manobra em mapas de sistemas de guia de rota. Bulletin of Geodetic Sciences, 20(2), pp. 317-333.

Ramos, A. P. M. et al. 2014c. Avaliação de erros de direção de manobra no uso de mapas em diferentes escalas em Sistemas de Guia de Rota. Brazilian Journal of Cartography, 6(1), pp. 13791393.

Ramos, A. P. M. et al. 2015. Influência do gênero na demanda visual por mapas em escalas diferentes em sistema de navegação e guia de rota. Bulletin of Geodetic Sciences, 21(1), p. 74-91.

Ramos, A. P. M. et al. 2016. Preference for map scale of In-Car Route Guidance and Navigation System. Bulletin of Geodetic Sciences, 22(3), pp. 472-491.

Ranney, T. A. Baldwin, G. H. S. and Smith, L. A. 2013. Driver behavior during visual-manual secondary task performance: occlusion method versus simulated driving. Available at: <https://www.nhtsa.gov/Research/Human-Factors/Distraction> [Accessed 18 March 2015].

Rigden, C. 1999. The eye of the beholder-designing for colour-blind users. British Telecommunications Engineering, 17(1), pp. 291-295.

Ross, T. and G. Burnett. 2001. Evaluating the human-machine interface to vehicle navigation systems as an example of ubiquitous computing. International Journal of Human-Computer Studies, 55(4), pp. 661-674. doi: 10.1006/ijhc.2001.0495

Sekuler, R. and Sekuler, A. B. 2000. Age-Related, Optical Factors and Neural Process. Encyclopedia of Psychology. American Psychological Association/Oxford University Press, 8(1), pp.180-183.

Shea, K. S. McMaster, R. B. 1992. Cartographic generalization in digital environment: when and how generalize. In: Autocarto 9, ACM/ASPRS, Baltimore, EUA. pp. 56-67. 
Sheleiby, M. Malek, M. R. and Alesheikh. 2008. Automatic Map Scaling in Car Navigation Systems Using Context-aware Computing. World Applied Sciences Journal, 3(1), pp. 101-106.

Slocum, T. Mcmaster, R. Kessler, F. Howard, H. 2009. Thematic Cartography and Geovisualization. 3rd ed. New Jersey: Pearson Prentice Hall, 576p.

Tsimhoni, O. Yoo, W. and Green, P. 1999. Effects of Workload and Task Complexity on Driving and Task Performance for In-Vehicle displays as Assessed by visual occlusion. Available at: <http://www.umich.edu/ driving/publications/UMTRI-99-37.pdf> [Accessed 13 July 2016].

Uang, S. T. and Hwang, S. L. 2003. Effects on driving behavior of congestion information and of scale of in-vehicle navigation systems. Transportation Research Part F, 1(11), pp.423-438.

Wickens, C. D., et al. 2004. An Introduction to Human Factors Engineering. 2nd ed. California: Pearson Prentice Hall. 608p.

Wikman, A. S. Nieminen, T. and Summala, H. 1998. Driving experience and time-sharing during incar tasks on roads of different width. Ergonomics, 41(3), pp.358-372.

doi: 10.1080/001401398187080

Wittmann, M. et al. 2006. Effects of display position of a visual in-vehicle task on simulated driving. Applied Ergonomics, 37(2), pp. 187-199. doi: 10.1016/j.apergo.2005.06.002

Wu, C. et al. 2013. Navigating a car in an unfamiliar country using an internet map: effects of street language formats, map orientation consistency, and gender on driver performance, workload and multitasking strategy. Behaviour \& Information Technology, 32(5), pp. 425-437.

Young, M. S. and Stanton, N. A. 2005. Mental Workload. In: Stanton, N. A.; et al. The handbook of human factors and ergonomics methods. USA: CRC Press LLC, p. 39-1; 39-9.

Young, M. S. and Stanton, N. A. 2006. Mental Workload: Theory, Measurement, and Application. In: Karwowski, W. International Encyclopedia of Ergonomics and Human Factors. 2. ed. USA: Taylor \& Francis, pp. 818-821. 